\title{
Gender Wise Relationship between Values and Moral Judgment of High School Students
}

\author{
E.Paul $^{1 *}$, H. Upadhyaya ${ }^{2}$
}

\section{ABSTRACT}

The main objective of the study was to find out the Gender wise relationship between Values and Moral Judgment of High School Students. For achieving the present objective of the study, the investigator used Descriptive Survey Research Method on 1200 High School students, 600 male and 600 females of Jabalpur district. The investigator administered scale of Values (by Dr. Kamla Vashishtha and Anju Jaideep) and Moral Judgment (by Ranjana Gupta). The raw score of Value and Moral Judgment were analysed with the help of Product Moment Method (Real Mean Method) and for significant difference between Value and Moral Judgment 2X2 Factoral Design ANOVA were used. The results revealed that there was significant correlation found at 0.01 level of significance only for girls and significant difference for main and joint effect of Value and Moral Judgment found at 0.01 .

Keywords: Value, Moral Judgment

Values are difficult to study and persistent questions arise as to whether they are 'real,' whether they actually can be shown to have causal influence on behaviour. Yet much of everyday life is cast in terms of values think of ethics, law, religion, politics, art, child rearing, and more. Abstract moral judgments are embodied in seeming gut reactions that something is right, moral, or natural vs. wrong, immoral, or unnatural. Another way to 'see' values in action is to contrast cultures or subcultures in what seems right, natural, or moral. Values contain a judgment element in that they carry on individual ideas as to what is good, right or desirable. It represents that a specific way of conduct is preferable to our opposite mode of conduct, they contain a judgment that what is, right or desirable. The moral judgment is the judgment which deals with the moral value or quality of an action. It is a judgment of value and it evaluates the rightness or wrongness of one's actions. When a moral judgment is analyzed then it is found that it contains: a subject which will judge, an object whose action will be judged, a standard in conformity to which the

\footnotetext{
${ }^{1}$ Research Scholar, Rani Durgavati Vishwavidhyalaya, Jabalpur M.P.,India

${ }^{2}$ H.O.D. Education Department, Hawabagh Women’s College, Jabalpur M.P., India

*Responding Author

Received: January 20, 2017; Revision Received: February 11, 2017; Accepted: February 15, 2017

(C) 2017 Paul E, Upadhyaya H; licensee IJIP. This is an Open Access Research distributed under the terms of the Creative Commons Attribution License (www.creativecommons.org/licenses/by/2.0), which permits unrestricted use, distribution, and reproduction in any Medium, provided the original work is properly cited.
} 
action of the subject will be judged and a power of judging the action as required. Generally, a moral judgment is given on the voluntary and habitual actions of a rational being. The voluntary actions of a rational person which involve deliberation, choice, and resolution, have the moral quality of rightness and wrongness. They are considered to be right or wrong with the reference to the moral standard. And on the basis of this standard, moral judgment is given. So to understand the relationship between the values and moral judgment the present research work has been done.

\section{Objective of the Study}

For the purpose of verifying the proposition in this area of the study, the framed objective is:

1. To study gender wise relationship between Values and Moral Judgment of high school students.

\section{Hypothesis}

1. There is no significant co-relationship between mean score of Value and Moral Judgment of high school students.

2. There is no significant individual and joint difference between mean score of Value and Moral Judgment of high school students.

\section{METHODOLOGY}

For achieving the objective of the present research work, Descriptive Survey Research Method was used. The present investigation employed correlational and $2 \times 2$ three way factorial analysis designs.

\section{Sample}

For achieving the objective of the study the investigator selected the sample of 1200 students (600 boys and 600 girls) of Class $9^{\text {th }}$ and $10^{\text {th }}$ through stratified random sampling technique, from the schools of Jabalpur district (M.P.)

\section{Tools of Study}

The tools for the present study are given below:

1. Value Test by Dr. Kamla Vashishtha \& Anju Jaideep

2. Moral Judgment Test by Ranjana Gupta

\section{Procedure}

In order to collect the data for the present study, the investigator administered the Value and Moral Judgment Test on 1200 students (600 boys and 600 girls) of class $9^{\text {th }}$ and $10^{\text {th }}$ of Jabalpur district (M.P.) and total raw scores of Value and Moral Judgment were obtained. 
Personality Factors as Determinants of Psychological Well-Being among University Students

Statistical Analysis

Mean, standard deviation and ANOVA test were used for testing the hypothesis of the present research work.

\section{RESULT AND INTERPRETATION}

Table No. $1 \mathrm{~N}, \bar{X}$, $\sigma$ and $r$ for Value and Moral Judgment of High School Boys

\begin{tabular}{|l|l|l|l|l|l|}
\hline Group & N & M & S.D. & r & “P” Value \\
\hline Value & 637 & 72.27 & 12.57 & 0.04 & $>0.05$ \\
\cline { 1 - 4 } Moral Judgment & 637 & 83.88 & 8.92 & & \\
\hline
\end{tabular}

$\mathrm{df}=636$

Min. Value at 0.05 level $=0.088$

Min. Value at 0.01 level $=0.125$

Table $2 \mathrm{~N}, \bar{X}, \sigma$ and $r$ for Value and Moral Judgment of High School Girls

\begin{tabular}{|l|l|l|l|l|l|}
\hline Group & N & M & S.D. & r & “P” Value \\
\hline Value & 563 & 74.60 & 14.41 & 0.18 & $<0.01$ \\
\cline { 1 - 4 } Moral Judgment & 563 & 83.76 & 8.57 & & \\
\hline
\end{tabular}

$\mathrm{df}=562$

Min. Value at 0.05 level $=0.088$

Min. Value at 0.01 level $=0.125$

Table $3 \mathrm{~N}, \bar{X}$, $\sigma$ and $r$ for Value and Moral Judgment of High School Students

\begin{tabular}{|l|l|l|l|l|l|}
\hline Group & N & M & S.D. & r & “P” Value \\
\hline Value & 1200 & 73.37 & 13.51 & 0.011 & $>0.01$ \\
\cline { 1 - 4 } Moral Judgment & 1200 & 83.83 & 8.75 & & \\
\hline
\end{tabular}

$\mathrm{df}=1199$

Min. Value at 0.05 level $=0.062$

Min. Value at 0.01 level $=0.081$

Table No. 4 Summary ANOVA Table

\begin{tabular}{|c|c|c|c|c|c|}
\hline Source of Variation & d.f. & $\begin{array}{l}\text { Sum of } \\
\text { Squares }\end{array}$ & $\begin{array}{l}\text { Mean } \\
\text { Square }\end{array}$ & F-Ratio & $\begin{array}{l}\text { "P" } \\
\text { Value }\end{array}$ \\
\hline $\begin{array}{l}\text { A. Value \& } \\
\text { Judgment }\end{array}$ & 1 & 65646.96 & 65646.96 & 508.74 & $<0.01$ \\
\hline B. Gender & 1 & 729.25 & 729.25 & 5.65 & $<0.01$ \\
\hline$A \times B$ & 1 & 2086.94 & 2086.94 & 16.17 & $<0.01$ \\
\hline Between & 3 & 68463 & 22821.05 & 176.85 & \\
\hline Within & 2396 & 309176.58 & 129.04 & & \\
\hline Total & 2399 & 377639.7 & & & \\
\hline $\mathrm{df}=2396 / 1$ & & & $\begin{array}{l}\text { Min. } \\
\text { Min. }\end{array}$ & $\begin{array}{l}0.05 \\
\text { it } 0.01\end{array}$ & $\begin{array}{l}l=2.60 \\
l=3.78\end{array}$ \\
\hline
\end{tabular}

(C) The International Journal of Indian Psychology, ISSN 2348-5396 (e) | ISSN: 2349-3429 (p) | 109 
Personality Factors as Determinants of Psychological Well-Being among University Students

Table No. 5 Group, Gender wise N, $\bar{X} \& \sigma$ of High School Students

\begin{tabular}{|l|l|l|l|l|}
\hline Group & Gender & N & M & S.D. \\
\hline \multirow{3}{*}{ Value } & Boys & 637 & 72.27 & 12.57 \\
\cline { 2 - 5 } & Girls & 563 & 74.60 & 14.41 \\
\cline { 2 - 5 } & Total & 1200 & 73.37 & 13.51 \\
\hline \multirow{3}{*}{ Moral Judgment } & Boys & 637 & 83.88 & 8.92 \\
\cline { 2 - 6 } & Girls & 563 & 83.76 & 8.57 \\
\cline { 2 - 5 } & Total & 1200 & 83.83 & 8.75 \\
\hline
\end{tabular}

1. Table No.1 evident that $r$ for Value and Moral Judgement of High School Boys was 0.04 which was not significant at 0.05 level with $\mathrm{df}=1 / 636$ found. It shows that there was a negligible positive but not significant correlation between Value and Moral Judgment of High School Boys. Thus, the Null Hypothesis No.1 (a). "There is no significant correlation between the mean score of Value and Moral Judgment of High School Boys" is not rejected. From Table No. 5 it is clearly stated that the mean score of Moral Judgment of High School Boys was 83.88 which is higher than the mean score of Value of High School Boys which was 72.27. It means that the boys are far better in Moral Judgment in comparison to their Value point of view. Similarly, the investigator realized at the time of data collection that the boys are more inclined towards the awareness of their rights but they have very little interest in their Values. That is why the mean score of Moral Judgment was found to be higher than the mean score of Values.

2. It is clearly indicated from Table No. 2 that $r$ for Value and Moral Judgement of High School Girls was 0.18 which was significant at 0.01 level with $\mathrm{df}=1 / 562$ found. It shows that there was a slight and negligible positive and significant correlation between value and moral Judgment of high School Girls. Thus, the Null Hypothesis No.1 (b). "There is no significant correlation between the mean score of Value and Moral Judgment of High School Girls” is rejected. The mean score of Value of High School Girls was found to be lesser than that of the mean score of Moral Judgment of High School Girls which was 74.60 and 83.76 respectively. But the mean score of Girl's Value and Moral Judgment was found to be slightly higher than that of boys as clearly shown in the Table No.4.5. The present finding is in accordance with the findings of Larden et.al. (2006) and Pal and Mishra (1992). They found that girls excelled boys in moral judgment. This may be due to the reason that moral judgment is influenced by one's environmental experiences. Females might have ever lasting influence of lesson taught by their parents' teachers, home environment, school and community in comparison to boys. Females are more mature, empathic and have less cognitive distortions (Larden et. al., 2006). Females are better able to judge situations as right or wrong since they have moral insight. However, contrary findings are of Mishra (995), and Padhan and Thakkar (1994). The former found that moral judgment is independent of sex and the latter found that no significant sex difference existed in development of moral judgment.

(c) The International Journal of Indian Psychology, ISSN 2348-5396 (e)| ISSN: 2349-3429 (p) | 110 
Personality Factors as Determinants of Psychological Well-Being among University Students

3. It is clearly indicated from Table No.3 that $r$ for Value and Moral Judgement of High School Students was 0.011 which was not significant at 0.01 level with $\mathrm{df}=1 / 1199$ found. It shows that there was a slight and negligible positive correlation between value and moral Judgment of high School Students. Thus, the Null Hypothesis No.1(c). "There is no significant correlation between the mean score of Value and Moral Judgment of High School Students" is not rejected. From Table No.4.5 it is clearly stated that the mean score of Moral Judgment of High School Students which was 83.83 was found to be higher than the Values of High School Students. Thus it can be said that the students are more aware of their right and wrong, good or bad. As per Matthew Feinberg "Moral Judgments are based on intuition. Our emotions seem to drive our intuitions, giving us the gut feeling that something is right or wrong."

4. It is clearly evident from Table No.4 that $\mathrm{F}$ value for Value and Moral Judgement was 508.74 which was significant at 0.01 level of significance with $\mathrm{df}=1 / 2396$. It shows that the mean score of Value and Moral Judgement differs significantly. So there is a significance difference between Value and Moral Judgement found. Thus the Null hypothesis No.2 (a), "There is no significant difference between mean score of Value and Moral Judgment of High School Student” is rejected. F value for Gender was 5.65, which was significant at 0.01 level of significance with $\mathrm{df}=1 / 2396$. It means that the mean score of boys and girls differ significantly. Thus the Null Hypothesis No.2 (b), "There is no significant difference between the mean score of Gender of High School Students" is rejected. $\mathrm{F}$ value for interactional difference among Value, Moral Judgment and Gender was 16.17, which was significant at 0.01 level of significance with $\mathrm{df}=2 / 12396$. It means that the mean score of Value, Moral Judgment of Boys and Girls differ significantly. Thus the Null Hypothesis No.2 (c), "There is no interactional difference among the mean score of Value, Moral Judgment and Gender" is rejected. Further the mean score of Boys for Value 72.27 which was significantly lower than the mean score of Moral Judgment 83.88. Similarly, the mean score of Girls for Value which was significantly lower than the mean score of Moral Judgment 83.76. Also, the mean score of Total Value 73.37 which was significantly lower that the Mean Score of Moral Judgment 83.83 (Vide Table No. 4.5 and clearly shown in Graph No. 4.1). The present findings is in accordance to the findings of Pratik Upadhyaya (2015) he found out that women as mothers and teachers play a vital role in the upbringing of children by handing over the baton on 'sanskar', values, moral ethics and spiritual values from one generation to another. So, it can be hoped that the present female adolescent students' showing high moral judgment will remove the dark shadows of dishonesty, selfishness, cruelty and immorality that are enveloping the modern generation. This will help in developing a healthy society. 
Personality Factors as Determinants of Psychological Well-Being among University Students

Graph No.1

Graph Showing Mean Scores of Value and Moral Judgment of High

School Students

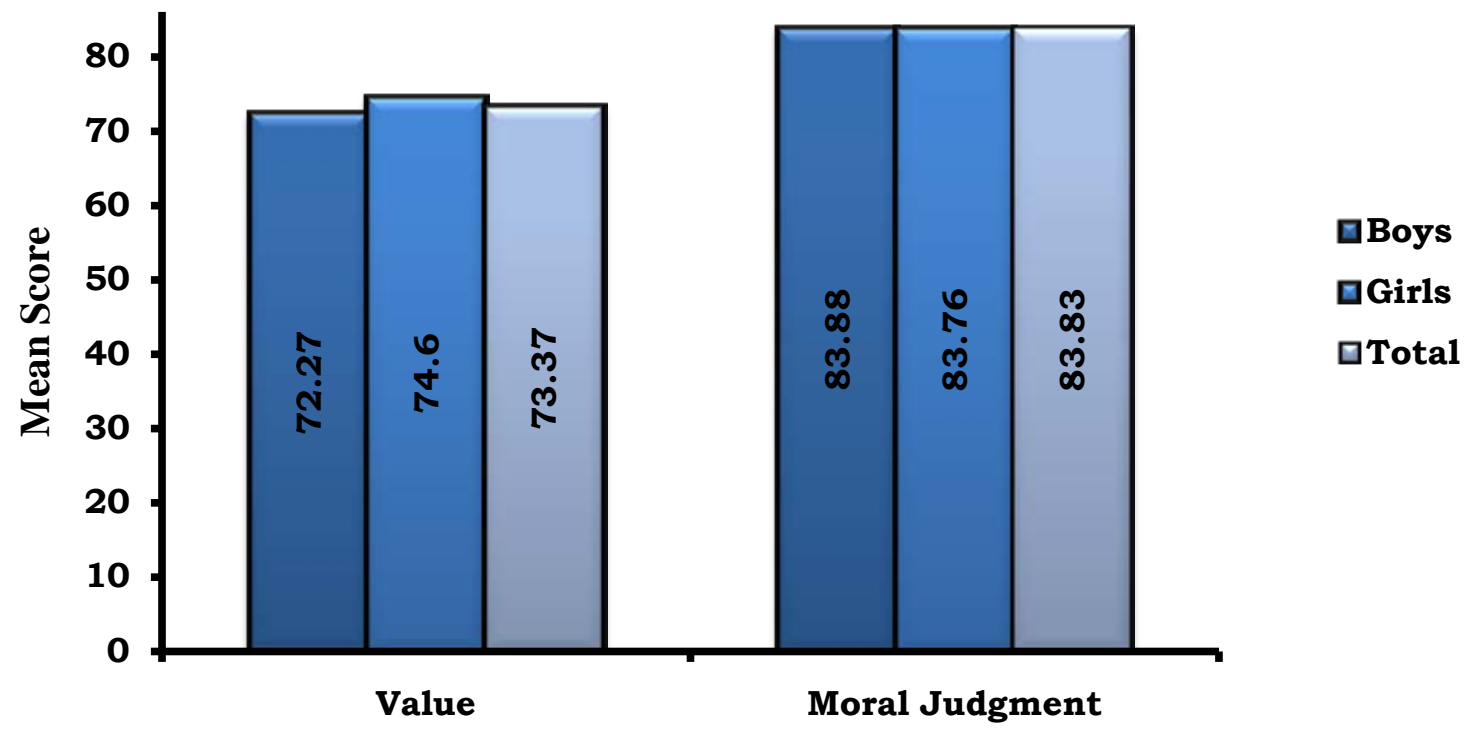

\section{CONCLUSION}

On the basis of the above discussion it is clear that,

1. Value of Girls was higher than the Value of Boys.

2. Not only the girls but the boys have also out beaten the girls by having high Moral Judgment.

3. Moral Judgment of High School Students was higher than the Values of High School Students.

\section{Acknowledgments}

The author appreciates all those who participated in the study and helped to facilitate the research process.

Conflict of Interests: The author declared no conflict of interests.

\section{REFERENCES}

Larden et. al. (2006). Moral Judgment, Cognitive Distortions And Empathy In Incarcerated Delinquent And Community Control Adolescents Psychology, Crime and Law 12(5) pp. 453-462 doi:10.1080/10683160500036855

Matthew, Feinberg (2012) Moral judgments 'based on intuition'.Syndigate.info an Albawaba.com company https://www.thefreelibrary.com/Moral+judgments+'based+on+intuition'a0303041046 


\section{Personality Factors as Determinants of Psychological Well-Being among University Students}

Mishra, K.P. (1995). Comparitive study of cognitive development model with motivation, social behaviour patterns and moral judgment of adolescents from deprived ecologies. Researches and Studies, 43, pp.1-7

Pal, S.K. and Misra, K.S. (1992). A study of cognitive process, academic motivation, social behaviour patterns and moral judgments of adolescents from deprived ecologies' Researcher and Studies, 43, pp. 1-7

Upadhyaya, Pratik (2015) "Gender Difference in Moral Judgment Among Secondary Level Students”, International Journal of Research Granthaalayah, Vol. 3, No. 11, pp. 1720.http://granthaalayah.com/Articles/Vol3Iss11/03_IJRG15_C11_23.pdf

How to cite this article: Paul E, Upadhyaya H (2017), Gender Wise Relationship between Values and Moral Judgment of High School Students, International Journal of Indian Psychology, Volume 4, Issue 2, No. 89, ISSN:2348-5396 (e), ISSN:2349-3429 (p), DIP:18.01.091/20170402, ISBN:978-1-365-74162-3 